
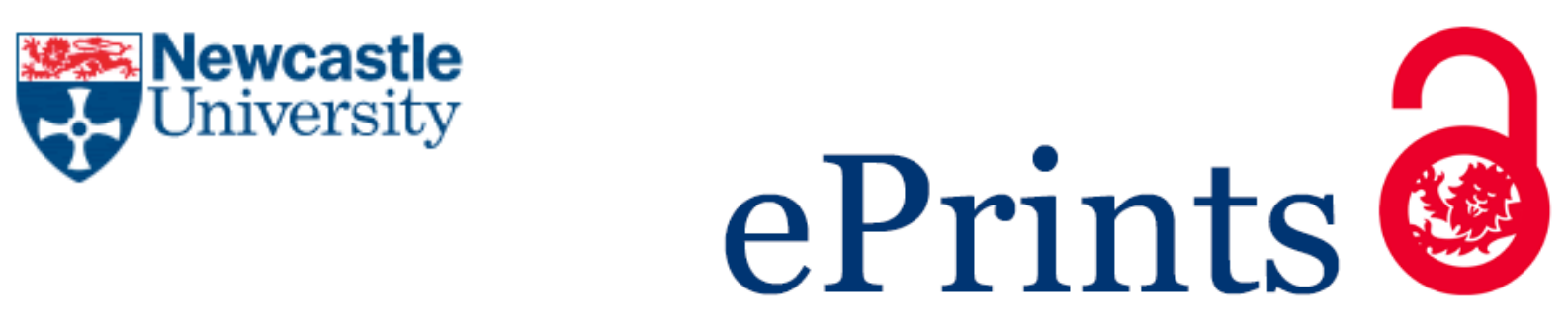

\author{
Langton DJ, Sidaginamale R, Joyce TJ, Meek RMD, Bowsher J, Deehan D, \\ Nargol A, Holland J. \\ A comparison study of stem taper material loss at similar and mixed metal \\ head neck taper junctions. \\ Bone and Joint Journal 2017, 99-B(10), 1304-1312.
}

\title{
Copyright:
}

This is the authors' accepted manuscript of an article that has been published in its final definitive form by The British Editorial Society of Bone \& Joint Surgery, 2017.

DOI link to article:

https://doi.org/10.1302/0301-620X.99B10.BJJ-2016-1005.R1

Date deposited:

$02 / 10 / 2017$

Embargo release date:

29 September 2018 


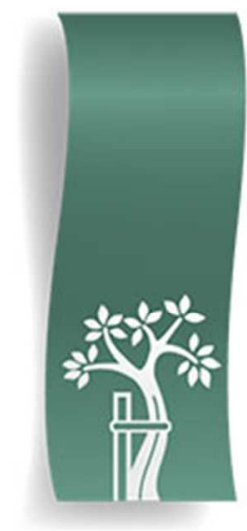

The

Bone \& Joint

Journal

Formerly known as JBJS (Br)

\section{A comparison study of stem taper material loss at similar and mixed metal head neck taper junctions}

\begin{tabular}{|r|l|}
\hline Journal: & The Bone \& Joint Journal \\
\hline Manuscript ID & Draft \\
\hline Manuscript Type: & Original Article \\
\hline Keywords: & $\begin{array}{l}\text { taper, explant, metal on metal, junction, mixed metals, arthroplasty, } \\
\text { volumetric wear, corrosion }\end{array}$ \\
\hline
\end{tabular}

\section{SCHOLARONE $^{\text {tx }}$}

Manuscripts 


\title{
A comparison study of stem taper material loss at similar and
}

\author{
mixed metal head neck taper junctions
}

Aims: We sought to determine whether CoCr femoral stem tapers wear more than Ti alloy stem tapers when used in a metal on metal (MoM) hip arthroplasty system.

Patients and Methods: We performed explant analysis using validated methodology to determine the volumetric material loss at the taper surfaces of explanted CoCr MoM hip arthroplasties used with either a Ti alloy $(n=30)$ or CoCr femoral stem $(n=21)$. Only 12/14 taper constructs were included, those with a rough male taper surface and a nominal included angle close to 5.66 degrees. Multiple regression modelling was undertaken using taper angle, taper roughness and bearing diameter as independent variables. Material loss was mapped using a coordinate measuring machine, profilometry and scanning electron microscopy.

Results: After adjustment for other factors, CoCr stem tapers were found to have significantly greater volumetric material loss than the equivalent Ti stem tapers.

Conclusion: When taper junction damage is identified at revision surgery, it should be suspected that a male taper composed of a standard CoCr alloy has sustained significant changes to the taper cone geometry which are likely to be more extensive than those affecting a Ti alloy stem.

\section{Background}

In the last five years there has been increasing awareness of the head neck taper junction as a contributing factor in the failure of large diameter (LD) metal on metal (MoM) hip devices.(1) This interface was studied extensively in the 1990s in a set of in vitro experiments. Several parameters were recognised to play a role in the successful function of this connection which included: head 
size; head offset; taper length; taper diameter; stem angle; stem roughness; head angle; head roughness; male/female angle mismatch; the straightness of the male/female taper and the conicity of the male/female tapers.(2)

At that time, concerns were raised regarding the use of mixed metallurgy taper junctions due to the perceived increased risk of corrosion.(3) The reported incidence of corrosion at the head neck junctions of hip arthroplasties ranges from 0 to $28 \%$ for $\mathrm{CoCr}$ on $\mathrm{CoCr}$ couples and up to $50 \%$ for $\mathrm{Ti}$ on $\mathrm{CoCr}$ couples(4-7). In one of the first large scale explant studies, Collier et al found no corrosion in similar $\mathrm{CoCr}$ on $\mathrm{CoCr}$ taper junctions.(6) The authors concluded that material loss was mediated via a galvanically-accelerated corrosive process rather than fretting wear as corrosion was identified only in mixed metal prostheses. Gilbert et al(8) subsequently presented the results of an analysis of 148 retrieved implants and showed that both mixed and similar metal combinations were corroding in upwards of $35 \%$ of mixed and $23 \%$ of similar metal tapers. These results contradicted those of Collier et al's, and a hypothesis was presented for the mechanism of attack whereby mechanically assisted crevice corrosion (MACC) (or fretting crevice corrosion) was taking place. Multiple subsequent in vitro studies have presented evidence consistent with MACC.(9)

The clinical impact of combining dissimilar alloys in taper junctions remains unclear. It has been shown that in junctions composed of a titanium alloy (Ti6Al4V)(Ti) stem and cobalt chrome ( $\mathrm{CoCrMo})(\mathrm{CoCr})$ head taper, the vast majority of material is lost from the $\mathrm{CoCr}$ surface. $(10,11)$ There is evidence to indicate that the softer Ti male taper can wear the female surface secondary to a galvanic corrosive process resulting in the deposition of a Ti oxide layer with a greater hardness than the CoCr surface.(12) Consistent with a wear phenomenon, it has been shown that rougher male and female taper surfaces are associated with greater rates of material loss at the female taper surface.(13)

To our knowledge, no studies thus far have used modern techniques including three-dimensional mapping to quantify and compare material loss at the male and female taper surfaces of similar and 
mixed metallurgical combinations. This study was carried out in order to address this issue. We hypothesised that $\mathrm{CoCr}$ stems, not protected by the corrosive process, would lose relatively more material than Ti alloy stems when used with a CoCr head.

\author{
Methods \\ Terminology \\ In this paper we use the terms "mixed" and "Ti on CoCr" to reference taper connections composed \\ of a Ti alloy femoral stem used in combination with a CoCr head. We use the terms "similar" and \\ "CoCr on CoCr" to reference taper connections composed of a CoCr femoral stem and CoCr head. \\ "Female taper" refers to the head taper surface and "male taper" refers to the femoral stem taper \\ or trunnion. \\ Samples
}

The Northern Retrieval Registry (NRR) is an initiative involving surgeons and engineers in the United Kingdom.(14) Analysis of explanted orthopaedic devices is conducted on a routine basis for all retrieved components in participating hospitals in the United Kingdom (NRES reference 09/H0905/41). From the total explant collection, the inclusion criteria for this study were: a MoM bearing surface; a nominal 12/14 taper construct with a male taper angle close to 5.666 degrees (the equivalent of a V40 design); a macroscopically ridged male taper surface and a known duration in vivo, patient age and patient sex

Explants were collected between 2008 and 2014. Components underwent volumetric wear assessment of the femoral and acetabular bearing surfaces as well as the taper surfaces. This was done with a coordinate measuring machine (CMM) (Legex322; Mitutoyo, Japan) using validated 
methodology. $(10,15)$ As well as quantification of material loss, these techniques also allow visualisation of the distribution of wear by the generation of a wear map. The practical approach and accuracy of such calculations are detailed in the Appendix. The surface topographies and cone angles of the male and female taper surfaces were measured using a SJ401 contacting profilometer (Mitutoyo) and the CMM respectively.

\section{Quantitative assessment of material loss}

The primary goal of this investigation was to determine whether material loss in similar metal taper junctions was more evenly distributed between the mated surfaces when compared to mixed metal junctions. A simple power analysis used to calculate the numbers needed in the two groups estimated that 20 samples would be needed to achieve significance. We used two statistical approaches - basic and complex.

Basic: A Mann Whitney test for non-parametric data was used to determine whether the ratio of the male to female taper material loss was significantly different between the mixed and similar metal groups. Then, in order to eliminate the possibility that the total amount of material loss at the junction might affect this ratio, a regression model was constructed using "similar" versus "mixed" as a categorical variable, with logged values of total volumetric taper wear as an independent continuous variable.

Complex: This approach attempted to account and adjust for other factors and to validate the results of the basic approach. Total volumetric wear values were converted initially to mean annual wear rates by dividing by the number of years in vivo. Spearman rank correlation was then used to examine the relationship of mean annual wear rates to each individual variable. Variables under investigation were: patient factors (sex; age at primary surgery) and design/implant factors (duration in vivo; female/male taper angle; taper surface roughness; angular mismatch). Femoral head offset was not included as these values are inconsistent between manufacturers' components. The results 
of these univariate tests determined which variables would then be entered into a multiple regression model.

\section{Multiple regression analysis}

Total volumetric values were log transformed to achieve an approximately normal distribution. With log transformed taper volume loss as the response variable, stepwise multiple regression was performed. Mixed versus similar metal taper junction was entered as a categorical variable. Three dependent variables were investigated: female taper volumetric loss; male taper volumetric loss and combined (male plus female) volumetric loss. Forward and backward stepwise approaches were used to ensure there were no practical differences in the statistical methods used.

\section{Characterisation of material loss}

CMM: Wear maps of female and male tapers were generated as part of the CMM analysis. The distribution of material loss in the two groups were compared non quantitatively.

Profilometry: Each explanted femoral stem underwent surface roughness analysis using the profilometer. Depending on the length of the male taper, 11 or $120.8 \mathrm{~mm}$ measurement traces were taken over the superior and inferior surfaces. These traces were taken sequentially from the base of the taper (position 1) to the tip (position 11 or 12). For each unit measurement the roughness average ( $\mathrm{Ra}$ ) was recorded. The mean Ra for each position was then calculated for the $\mathrm{CoCr}$ and Ti stems and plotted in order to identify trends in material loss. With stems with ridged surfaces, material loss leads to removal of the tips of the ridges and therefore material loss reduces the Ra value.

Scanning electron microscopy (SEM): Due to the size restrictions of the chamber of our electron microscope, male tapers either had to be sectioned or a component of a dual modular stem system in order to undergo SEM. Therefore, without destructive testing, only two male taper specimens could be examined. They were a Depuy Solution CoCr stem (sectioned at revision) and a Zimmer 
Kinectiv Ti stem. These samples were not part of the current study due to lack of accompanying clinical data. However, they were deemed appropriate to act as representative samples following consideration of the profilometry and $\mathrm{CMM}$ findings, and the modular stem having no significant surface changes at the distal modular junction. The mated female head tapers were also examined using the SEM, along with ten CoCr heads (five used with Ti stems and five used with CoCr stems) used in the study.

\section{Results}

A total of 51 hips were examined from 51 patients. Implant details and patient demographics are shown in table 1 . The details of the tapers analysed in the study are shown in table 2.

Basic statistical approach: In the mixed metal group, the median ratio of female to male volumetric material loss was 3.34. The equivalent value for the similar metal group was 1.61. This difference was significant ( $p=0.007)$. In 6 of the 51 female tapers the material loss was below the level of measurement error. Figure 1 shows the spread of female to male material loss ratios with these 6 results removed. The regression model, which accounted for total material loss, also showed that the difference in the ratio of material loss between the male and female surfaces in the similar and mixed groups was significant $(p<0.001)$ (figure 2$)$.

Univariate analysis

Results of the univariate analysis are shown in table 3. Bearing diameter was found to be the variable with the greatest power to explain the variation in taper wear rates (figure 3).

Multiple regression analysis

https://mc04.manuscriptcentral.com/bjj 
Stepwise regression models returned consistent results using either forward, backward or best fitting methods. The results given below were generated from the results of the best fitting models.

1. Female taper material loss (table 4). The best fitting regression model returned an $\mathrm{R}^{2}$ value of $48 \%$. Bearing diameter alone provided approximately $18 \%$ of the variation in the taper wear measurements. Duration in vivo was the next most influential variable, with metallurgical combination, female taper angle and female Ra contributing smaller, equal amounts to the model.

2. Male taper material loss (table 5). The best fitting regression model returned an $R^{2}$ value of $71 \%$. The dominant variable here was clearly the type of junction, which provided $63 \%$ of the explanation for the variation in male taper material loss, with the magnitude of male taper material loss being significantly greater in CoCr stems.

3. Combined (male and female) material loss (table 6). As most of the material in the 51 examined taper junctions was lost from the female taper surface, these results mirrored those of the female taper model. The best fitting regression model returned an $R^{2}$ value of $50 \%$. Bearing diameter alone provided approximately $26 \%$ of the variation in the taper wear measurements. Duration in vivo was the next most influential variable, providing $11 \%$, with female taper angle and female Ra contributing smaller, equal amounts to the model. Although there was a trend towards less material loss with similar metal junctions, this was found to be non-significant in this model $(p=0.185)$.

A final model was constructed in order to confirm the above findings. This time, male volumetric loss acted as the dependent variable and female taper volumetric loss was added as an explanatory variable. The $\mathrm{R}^{2}$ value was $73 \%$ with approximately $64 \%$ of the variation explained by the type of connection, with $\mathrm{CoCr}$ male tapers losing significantly greater amounts of material than Ti tapers $(p<0.001) .10 \%$ of the variation was explained by total volumetric loss from the female surface.

\section{Characterisation of material loss}




\section{Quantitative assessment}

Overall, the Ra values of the CoCr tapers were significantly lower than the Ti tapers, indicating greater amounts of material loss, a finding consistent with those derived from the CMM analysis (figure 4). The profilometry measurements taken from the $\mathrm{CoCr}$ and $\mathrm{Ti}$ stem tapers were similar in that the lowest Ra values (greatest material loss) were found at the base of the tapers.

\section{Qualitative assessment}

CMM: The site of maximal loss at the female taper surface invariably corresponded to the engagement with the base of the male taper, irrespective of manufacturer or mixed versus similar metal junctions. Representative wear maps are shown in figure 5.

SEM: Typical findings at the site of maximal damage at the female surfaces are shown in figure 6. Profilometry: Mean Ra values obtained at each male taper position are shown in figure 7. Typically, the surface ridges were preferentially lost at the base (distal aspect) of the taper surfaces. This was confirmed using SEM analysis (figure 8).

\section{Discussion}

The release of metal debris from the head neck junction has been recognised as a potential clinical risk for decades.(16) Unfortunately, the development of knowledge in this area has been limited by a lack of available explant data. Standard methodology used to analyse these devices also remains relatively primitive. An early study involving the examination of 231 explanted hips by Goldberg et al(17) employed a now widely accepted visual four point grading scale to assess the damage at the material surfaces. Most contemporary studies continue to rely on this grading scale. While a visual assessment does identify damage there is a clear ceiling effect. In our experience, the vast majority of tapers with greater than $0.5 \mathrm{~mm}^{3}$ cubed of volumetric loss achieve the maximum score of 
"Goldberg 4." 19 of the 21 (90\%) similar metal female tapers in this study would have achieved a maximum Goldberg score, compared to only $53 \%$ in the mixed metal group. The conclusions of this study would have been completely different had the Goldberg scale been used to gauge the extent of taper damage.

To our knowledge, only in the last five years has volumetric wear analysis been conducted on failed tapers. At the time of writing we were unable to identify more than five studies with volumetric results. A review of the literature indicates that authors continue to give equal weighting to studies irrespective of whether visual or volumetric results are reported.(18) The aim of this investigation was to quantify, using modern techniques, the relative amount of material loss at the surfaces of mixed versus similar metal taper junctions.

There are limitations to the study. The first is the fundamental nature of retrieval studies in which the samples, by definition, were not functioning optimally. The reported results should therefore not be taken in isolation but placed into the wider clinical context along with information from joint registries. The second limitation arose due to the fact that in the United Kingdom the use of uncemented CoCr stems is relatively rare.(19) This meant, therefore, that the majority of the $\mathrm{CoCr}$ stems in this study were cemented. We do not believe however, that these factors should affect the proportion of material loss from the male and female components, which was the primary outcome measure in this study.

In context with the existing body of literature, the current study has several strengths: the use of accurate methodology to produce quantitative results with clinical significance(20) and the measurement and control of factors previously shown to be of importance, either by selection criteria or basic statistical adjustment. The results appeared to be unequivocal and consistent between manufacturers. $\mathrm{CoCr}$ stem tapers lost more material than Ti tapers which had been used with similar CoCr heads. 
Why does a CoCr stem lose more material than a Ti stem?

Authors have hypothesized that a combination of crevice, oxide fracture and galvanism result in a preferential attack of the CoCr alloy taper surface.(3) As discussed above, the Goldberg scale $(17,21)$ is a "corrosion score". In the majority of explants in this study there was widespread blackened debris extending distal to the engagement area, an observation which would lead to a higher corrosion score. Yet this debris did not represent corrosion of the original surface but debris deposition ("metal on", not "metal off"). It could be argued that the widespread use of the Goldberg scale has become self-perpetuating in reinforcing the belief that corrosion is the key mechanism of material loss at the taper junction.

The physical appearances of the taper surfaces do not appear wholly consistent with a corrosive effect.(15) In the first instance, the changes at the female surface appeared similar whether they had been used with a Ti or CoCr stem. In the area of maximal damage, which corresponded to the area interacting with the base of the trunnion, there was an abrupt transition from the original manufacturing marks to an area which appeared to have been smoothed over, as if polished. There were pits consistent with corrosion, but these areas represented a small proportion of the total area of material removal. And in both mixed and similar metal groups, the observed damage to the male and female taper surfaces sequentially decreased the deeper into the taper crevice the examination took place. These findings would not be consistent with typical pitting or crevice corrosion which would lead to diffuse changes in the $\mathrm{pH}$ of the taper environment and dissolution of the metal surfaces.(3) We have previously conducted an in depth examination of the phenomenon of a softer Ti alloy imprinting on to a harder CoCr surface and found that this finding could indeed result from a mechanical process.(12)

Why is the material loss primarily from the female surface even in similar metal junctions? We do not currently have the explanation for this. We do however refer to our experience with femoral and acetabular bearing surfaces in MoM systems. In the majority of, but not all, cases there is much 
greater material loss from the femoral head when compared to the mating acetabular

component.(22)

The importance of bearing size. In our previous work focusing on Depuy products we found evidence that the size of the lever arm acting on the taper junction was a critical factor in taper failure.(23) The main constituent of the lever arm distance is head size. In the current study we have again shown that bearing diameter is of paramount importance (figure 3). Larger diameter femoral heads provide a simple mechanical means by which tapers may fail. The increased use of LD components over the last 15 years also provides a logical explanation for the increasing recognition of taper debris as an important mode of failure in contemporary hip arthroplasty.(19)

\section{Clinical implications}

When taper junction damage is identified at revision surgery, it should be suspected that a male taper composed of $\mathrm{CoCr}$ has sustained significant changes to the taper cone geometry. These changes in form are likely to be appreciably greater than those affecting a Ti stem. We therefore advise against the impaction of a metal head on to an existing $\mathrm{CoCr}$ stem. The results underline the importance of mechanical factors in the function of the head neck taper connection and we urge caution in the use of LD heads without suitable optimisation of the taper connection, irrespective of the bearing material.

\section{Tables}

Table 1. Patient and implant details.

\begin{tabular}{|l|c|c|c|}
\hline & Ti on CoCr & CoCr on CoCr & Significance \\
\hline Number & 30 & 21 & NA \\
\hline Male:Female & $14: 16$ & $13: 8$ & 0.351 \\
\hline
\end{tabular}




\begin{tabular}{|l|c|c|c|}
\hline Reason for revision & $30(100 \%)$ ARMD $)$ & $21(100 \%)$ ARMD & NA \\
\hline $\begin{array}{l}\text { Duration in vivo } \\
\text { (months) }\end{array}$ & $57(16-108)$ & $45(28-102)$ & 0.013 \\
\hline Uncemented $(\mathrm{n})$ & 30 & 0 & $<0.001$ \\
\hline Age (years) & $62(28-82)$ & $59(26-75)$ & 0.164 \\
\hline $\begin{array}{l}\text { Bearing diameter } \\
\text { (mm) }\end{array}$ & $39(36-54)$ & $50(42-56)$ & $<0.001$ \\
\hline $\begin{array}{l}\text { Bearing wear rate } \\
\text { (mm } 3 \text { /year) }\end{array}$ & $1.28(0.26-40.2)$ & $1.65(0.65-5.12)$ & 0.233 \\
\hline $\begin{array}{l}\text { Male taper wear rate } \\
\text { (mm } 3 \text { /year) }\end{array}$ & $0.04(0.01-0.12)$ & $0.30(0.03-0.53)$ & $<0.001$ \\
\hline $\begin{array}{l}\text { Female taper material } \\
\text { loss (mm }{ }^{3} / \text { year) }\end{array}$ & $0.11(0.01-2.16)$ & $0.41(0.01-1.65)$ & 0.042 \\
\hline Female:male loss & 3.34 & 1.61 & 0.007 \\
\hline Male taper angle $\left(^{\circ}\right)$ & $5.667(5.634-5.713)$ & $5.672(5.650-5.707)$ & 0.172 \\
\hline $\begin{array}{l}\text { Mean female taper } \\
\text { angle }\left(^{\circ}\right)\end{array}$ & $5.646(5.581-5.784)$ & $5.644(5.562-5.774)$ & 0.767 \\
\hline $\begin{array}{l}\text { Mean female Ra } \\
\text { (microns) }\end{array}$ & $0.739(0.166-2.237)$ & $1.140(0.561-2.697)$ & 0.003 \\
\hline
\end{tabular}

Table 2. Details of femoral stem and female tapers involved in the study.

\begin{tabular}{|l|c|c|c|c|c|c|c|c|}
\hline & Fixation & $\mathrm{N}$ & Alloy & $\begin{array}{c}\text { Stem } \\
\text { shaft } \\
\text { angle }\end{array}$ & $\begin{array}{c}\text { Distance } \\
\text { between } \\
\text { peaks }(\mu)\end{array}$ & $\begin{array}{c}\text { Mean } \\
\text { peak } \\
\text { heights } \\
(\mu)\end{array}$ & Ra $(\mu)$ & $\begin{array}{c}\text { Taper } \\
\text { surface } \\
\text { length } \\
(\mathrm{mm})\end{array}$ \\
\hline $\begin{array}{l}\text { Corail } \\
\text { (DePuy) }\end{array}$ & $\mathrm{U}$ & 28 & Ti6Al4V & $125 / 135$ & $180-210$ & 15 & 4.168 & 10.1 \\
\hline $\begin{array}{l}\text { CPT } \\
\text { (Zimmer) }\end{array}$ & $\mathrm{C}$ & 16 & CoCrMo & 125 & 206 & 15 & 4.022 & 12.2 \\
\hline $\begin{array}{l}\text { Spitorno } \\
\text { (Zimmer) }\end{array}$ & $\mathrm{U}$ & 1 & Ti6Al4V & 135 & 143 & 35 & 9.741 & 11.3 \\
\hline $\begin{array}{l}\text { CPCS } \\
\text { (Smith } \\
\text { and } \\
\text { Nephew) }\end{array}$ & $\mathrm{C}$ & 5 & $\begin{array}{c}\text { CoCrMo } \\
\text { (ASTMF799) }\end{array}$ & 131 & 215 & 15 & 3.671 & 10.9 \\
\hline $\begin{array}{l}\text { Synergy } \\
\text { (Smith } \\
\text { and } \\
\text { Nephew) }\end{array}$ & $\mathrm{U}$ & 1 & Ti6Al4V & 131 & 190 & 15 & 3.501 & 10.0 \\
\hline
\end{tabular}




\begin{tabular}{|l|c|c|c|c|c|c|c|c|}
\hline \multicolumn{7}{|c|}{ Female tapers } & \\
\hline $\begin{array}{l}\text { ASR } \\
\text { (sleeved) }\end{array}$ & NA & 6 & $\begin{array}{c}\text { CoCrMo } \\
\text { (ASTM } \\
\text { F799) }\end{array}$ & NA & 23 & NA & 0.293 & NA \\
\hline $\begin{array}{l}\text { BHR } \\
\text { modular } \\
\text { (sleeved) }\end{array}$ & NA & 6 & $\begin{array}{c}\text { CoCrMo } \\
\text { ISO5832-12 }\end{array}$ & NA & 74 & NA & 0.694 & NA \\
\hline $\begin{array}{l}\text { Pinnacle } \\
\text { Ultamet }\end{array}$ & NA & 22 & $\begin{array}{c}\text { CoCrMo } \\
\text { ASTM } \\
\text { F1537 }\end{array}$ & NA & 62 & NA & 0.902 & NA \\
\hline $\begin{array}{l}\text { Zimmer } \\
\text { Metasul } \\
\text { LDH } \\
\text { (sleeved) }\end{array}$ & NA & 17 & $\begin{array}{c}\text { CoCrMo } \\
\text { ASTM } \\
\text { F1537 }\end{array}$ & NA & 56 & NA & 1.179 & NA \\
\hline
\end{tabular}

Table 3. Results of univariate analysis.

\begin{tabular}{|l|c|c|c|c|}
\hline Variable & $\begin{array}{c}\text { Relationship to } \\
\text { combined taper } \\
\text { wear rate (mixed) }\end{array}$ & Significance & $\begin{array}{c}\text { Relationship to } \\
\text { combined } \\
\text { taper wear rate } \\
\text { (similar) }\end{array}$ & Significance \\
\hline Sex (M vs F) & 0.10 vs 0.19 & 0.980 & 0.90 vs 0.37 & 0.066 \\
\hline Age & 0.135 & 0.490 & -0.273 & 0.325 \\
\hline Bearing wear & -0.118 & 0.565 & 0.365 & 0.087 \\
\hline Female taper & $\mathbf{0 . 4 3 0}$ & 0.018 & -0.001 & 0.998 \\
angle & -0.315 & 0.099 & 0.083 & 0.704 \\
\hline Angular mismatch & $\mathbf{0 . 4 0 2}$ & $\mathbf{0 . 0 2 9}$ & 0.291 & \\
\hline
\end{tabular}




\begin{tabular}{|l|l|l|l|l|}
\hline Bearing diameter & $\mathbf{0 . 4 0 2}$ & $\mathbf{0 . 0 2 8}$ & $\mathbf{0 . 6 8 4}$ & $<0.001$ \\
\hline Female Ra & 0.069 & 0.719 & 0.232 & 0.284 \\
\hline Female Rpk & -0.019 & 0.922 & 0.113 & 0.606 \\
\hline
\end{tabular}

Table 4. Results of best fitting multiple regression model for total volumetric material loss at the female taper surface. Bearing wear rate was rejected from the model $(-0.205 ; p=0.118)$ as was angular mismatch of taper $(0.283 ; p=0.452)$.

\begin{tabular}{|l|l|l|l|l|l|l|}
\hline Variable & Value & $\begin{array}{l}\text { Standard } \\
\text { error }\end{array}$ & $\mathrm{t}$ & $\mathrm{Pr}>|\mathrm{t}|$ & $\begin{array}{l}\text { Lower } \\
\text { bound } \\
(95 \%)\end{array}$ & $\begin{array}{l}\text { Upper } \\
\text { bound } \\
(95 \%)\end{array}$ \\
\hline Duration & 0.390 & 0.120 & 3.258 & 0.002 & 0.149 & 0.631 \\
\hline Female taper angle & 0.269 & 0.108 & 2.548 & 0.019 & 0.047 & 0.490 \\
\hline Bearing diameter & 0.697 & 0.165 & 4.764 & $<0.001$ & 0.361 & 1.033 \\
\hline Female Ra & 0.246 & 0.113 & 2.494 & 0.045 & 0.006 & 0.487 \\
\hline CoCr on CoCr & -0.331 & 0.144 & -2.855 & 0.061 & -0.677 & 0.015 \\
\hline
\end{tabular}

Table 5. Results of best fitting multiple regression model for total volumetric material loss at the male taper surface.

\begin{tabular}{|l|c|c|c|c|c|c|}
\hline Source & Value & $\begin{array}{c}\text { Standard } \\
\text { error }\end{array}$ & $\mathrm{t}$ & $\operatorname{Pr}\rangle|\mathrm{t}|$ & $\begin{array}{c}\text { Lower } \\
\text { bound } \\
(95 \%)\end{array}$ & $\begin{array}{c}\text { Upper } \\
\text { bound } \\
(95 \%)\end{array}$ \\
\hline Bearing diameter & 0.264 & 0.124 & 2.133 & 0.039 & 0.015 & 0.514 \\
\hline
\end{tabular}




\begin{tabular}{|l|c|c|c|c|c|c|}
\hline CoCr on CoCr & 0.580 & 0.128 & 4.542 & $<0.0001$ & 0.015 & 0.514 \\
\hline Female Ra & 0.161 & 0.089 & 1.814 & 0.077 & -0.018 & 0.339 \\
\hline Taper Angle & -0.156 & 0.082 & -1.908 & 0.063 & -0.320 & 0.009 \\
\hline
\end{tabular}

Table 6. Results of best fitting multiple regression model for total volumetric material loss at the taper surfaces (male and female surfaces combined).

\begin{tabular}{|l|c|c|c|c|c|c|}
\hline Variable & Value & $\begin{array}{c}\text { Standard } \\
\text { error }\end{array}$ & $\mathrm{t}$ & $\operatorname{Pr}>|\mathrm{t}|$ & $\begin{array}{c}\text { Lower } \\
\text { bound } \\
(95 \%)\end{array}$ & $\begin{array}{c}\text { Upper } \\
\text { bound } \\
(95 \%)\end{array}$ \\
\hline Duration & 0.344 & 0.117 & 2.933 & 0.005 & 0.108 & 0.580 \\
\hline Female taper angle & 0.185 & 0.108 & 1.716 & 0.093 & -0.032 & 0.402 \\
\hline Bearing diameter & 0.732 & 0.163 & 4.478 & $<0.0001$ & 0.403 & 1.061 \\
\hline Ra & 0.252 & 0.117 & 2.159 & 0.036 & 0.017 & 0.488 \\
\hline CoCr on CoCr & -0.227 & 0.168 & -1.346 & 0.185 & -0.566 & 0.113 \\
\hline
\end{tabular}


1. Meyer H, Mueller T, Goldau G, Chamaon K, Ruetschi M, Lohmann CH. Corrosion at the cone/taper interface leads to failure of large-diameter metal-on-metal total hip arthroplasties. Clinical orthopaedics and related research. 2012;470(11):3101-8.

2. Marlowe DE, Parr JE, Mayor MB. Modularity of orthopedic implants: ASTM International; 1997.

3. Jacobs JJ, Gilbert JL, Urban RM. Current Concepts Review-Corrosion of Metal Orthopaedic Implants*. The Journal of Bone \& Joint Surgery. 1998;80(2):268-82.

4. Collier JP, Mayor MB, Williams IR, Surprenant VA, Surprenant HP, Currier BH. The Tradeoffs Associated With Modular Hip Prostheses. Clinical orthopaedics and related research. 1995;311:91101.

5. Collire JP, Surprenant VA, Jensen RE, Mayor MB. Corrosion at the Interface of Cobalt-Alloy Heads on Titanium-Alloy Stems. Clinical orthopaedics and related research. 1991;271:305.

6. Collier JP, Surprenant VA, Jensen RE, Mayor MB, Surprenant HP. Corrosion between the components of modular femoral hip prostheses. Bone \& Joint Journal. 1992;74(4):511-7.

7. Cook SD, Barrack RL, Clemow A. Corrosion and wear at the modular interface of uncemented femoral stems. Bone \& Joint Journal. 1994;76(1):68-72.

8. Gilbert JL, Buckley CA, Jacobs JJ. In vivo corrosion of modular hip prosthesis components in mixed and similar metal combinations. The effect of crevice, stress, motion, and alloy coupling. Journal of biomedical materials research. 1993;27(12):1533-44.

9. Jacobs JJ, Cooper HJ, Urban RM, Wixson RL, Della Valle CJ. What do we know about taper corrosion in total hip arthroplasty? J Arthroplasty. 2014;29(4):668-9.

10. Bone MC, Sidaginamale RP, Lord JK, Scholes SC, Joyce TJ, Nargol AV, et al. Determining material loss from the femoral stem trunnion in hip arthroplasty using a coordinate measuring machine. Proc Inst Mech Eng H. 2015;229(1):69-76.

11. Matthies AK, Racasan R, Bills P, Blunt L, Cro S, Panagiotidou A. Material loss at the taper junction of retrieved large head metal-on-metal total hip replacements. J Orthop Res. 2013;31. 
12. Moharrami N, Langton DJ, Sayginer O, Bull SJ. Why does titanium alloy wear cobalt chrome alloy despite lower bulk hardness: A nanoindentation study? Thin Solid Films. 2013;549:79-86.

13. Brock TM, Sidaginamale R, Rushton S, Nargol AV, Bowsher JG, Savisaar C, et al. Shorter, rough trunnion surfaces are associated with higher taper wear rates than longer, smooth trunnion surfaces in a contemporary large head metal-on-metal total hip arthroplasty system. J Orthop Res. 2015;33(12):1868-74.

14. Langton DJ, Sidaginamale RP, Avery P, Waller S, Tank G, Lord J, et al. Retrospective cohort study of the performance of the Pinnacle metal on metal (MoM) total hip replacement: a singlecentre investigation in combination with the findings of a national retrieval centre. BMJ Open. 2016;6(4):e007847.

15. Langton DN, AVF, Joyce, TJ. Investigation of taper failure in a contemporary metal on metal hip arthroplasty system through examination of unused and explanted prostheses Journal of Bone and Joint Surgery, American Volume. In press.

16. Jacobs JJ, Gilbert JL, Urban RM. Corrosion of metal orthopaedic implants. The Journal of bone and joint surgery American volume. 1998;80(2):268-82.

17. Goldberg JR, Gilbert JL, Jacobs JJ, Bauer TW, Paprosky W, Leurgans S. A multicenter retrieval study of the taper interfaces of modular hip prostheses. Clinical orthopaedics and related research. 2002;401:149-61.

18. Esposito Cl, Wright TM, Goodman SB, Berry DJ. What is the trouble with trunnions? Clinical Orthopaedics and Related Research ${ }^{\circledR}$. 2014;472(12):3652-8.

19. 12th Annual Report. National Joint Registry of England and Wales. 2015.

20. Sidaginamale R. The Clinical Implications of Metal Debris Release from the Taper Junctions and Bearing Surfaces of Metal on Metal Hip Arthroplasty. Part One: Joint Fluid and Blood Metal Ion Concentrations. Bone \& Joint Journal. 2016; In press. 
21. Hothi HS, Matthies AK, Berber R, Whittaker RK, Skinner JA, Hart AJ. The reliability of a scoring system for corrosion and fretting, and its relationship to material loss of tapered, modular junctions of retrieved hip implants. J Arthroplasty. 2014;29(6):1313-7.

22. Lord JK, Langton DJ, Nargol AVF, Joyce TJ. Volumetric wear assessment of failed metal-onmetal hip resurfacing prostheses. Wear. 2011;272(1):79-87.

23. Langton DJ, Sidaginamale R, Lord JK, Nargol AV, Joyce TJ. Taper junction failure in largediameter metal-on-metal bearings. Bone Joint Res. 2012;1(4):56-63. 
1

2

3

4

5

6

7

8

9

10

11

12

13

14

15

16

17

18

19

20

21

22

23

24

25

26

27

28

29

30

31

32

33

34

35

36

37

38

39

40

41

42

43

44

45

46

47

48

49

50

51

52

53

54

55

56

57

58

59

60

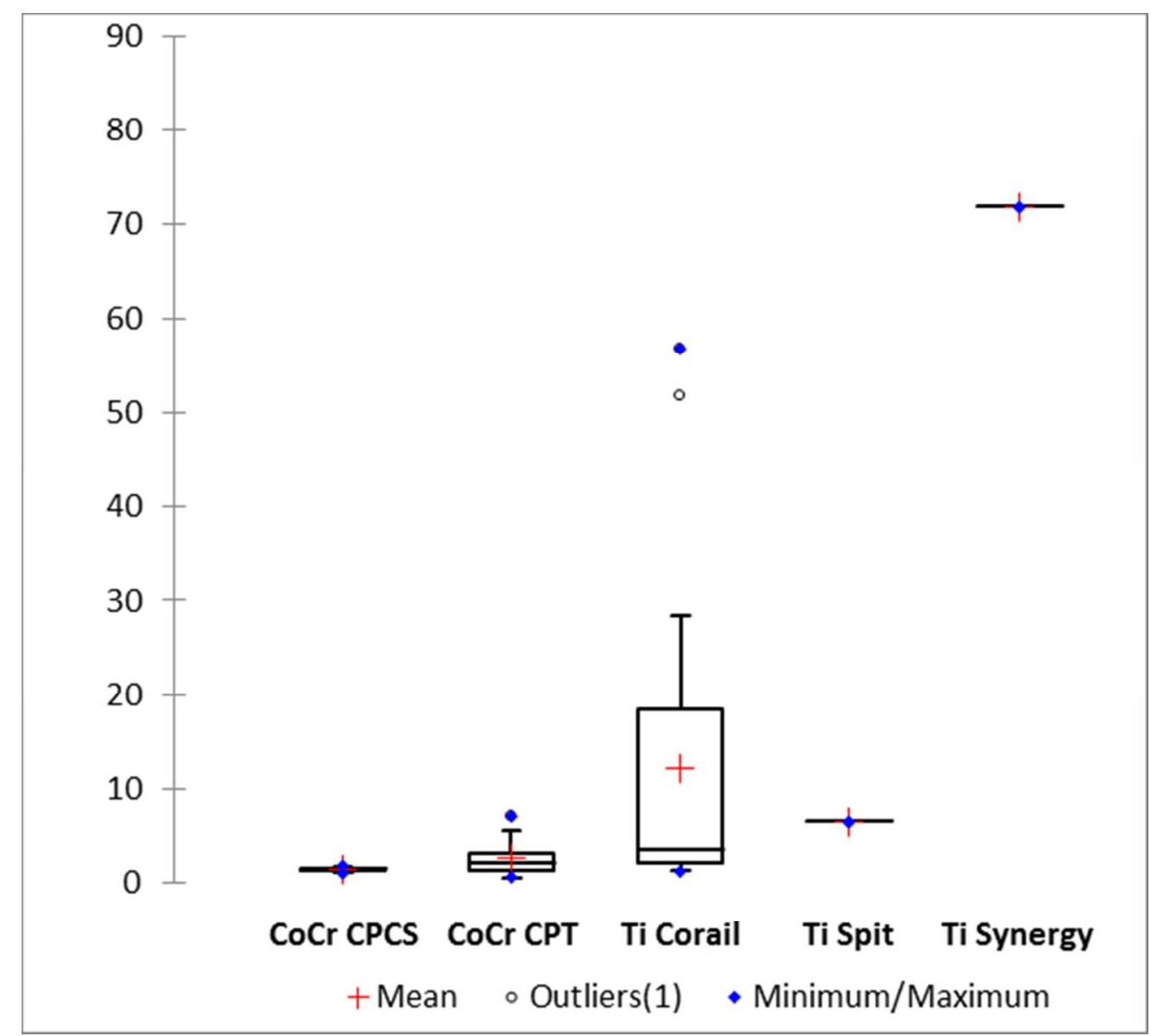

Figure 1: This box and whisker plot illustrates the ratios of volumetric material loss of the explants in the study. For example, if the volumetric loss from the female taper was $3 \mathrm{~mm} 3$, and that from the corresponding male taper was 1 , the ratio would be 3 . The boxes represent the interquartile distribution and the whiskers the range of the data. The horizontal line represents the median value. Only explants in which the female material loss was greater than the measurement error are included in this chart.

$204 \times 185 \mathrm{~mm}(150 \times 150 \mathrm{DPI})$ 
Figure 2: Scatter chart to illustrate the relationship between the volumetric loss from the male and female taper surface for the similar and mixed metal groups.

$159 \times 144 \mathrm{~mm}(96 \times 96 \mathrm{DPI})$ 
6

7

8

9

10

11

12

13

14

15

16

17

18

19

20

21

22

23

24

25

26

27

28

29

30

31

32

33

34

35

36

37

38

39

40

41

42

43

44

45

46

47

48

49

50

51

52

53

54

55

56

57

58

59

60

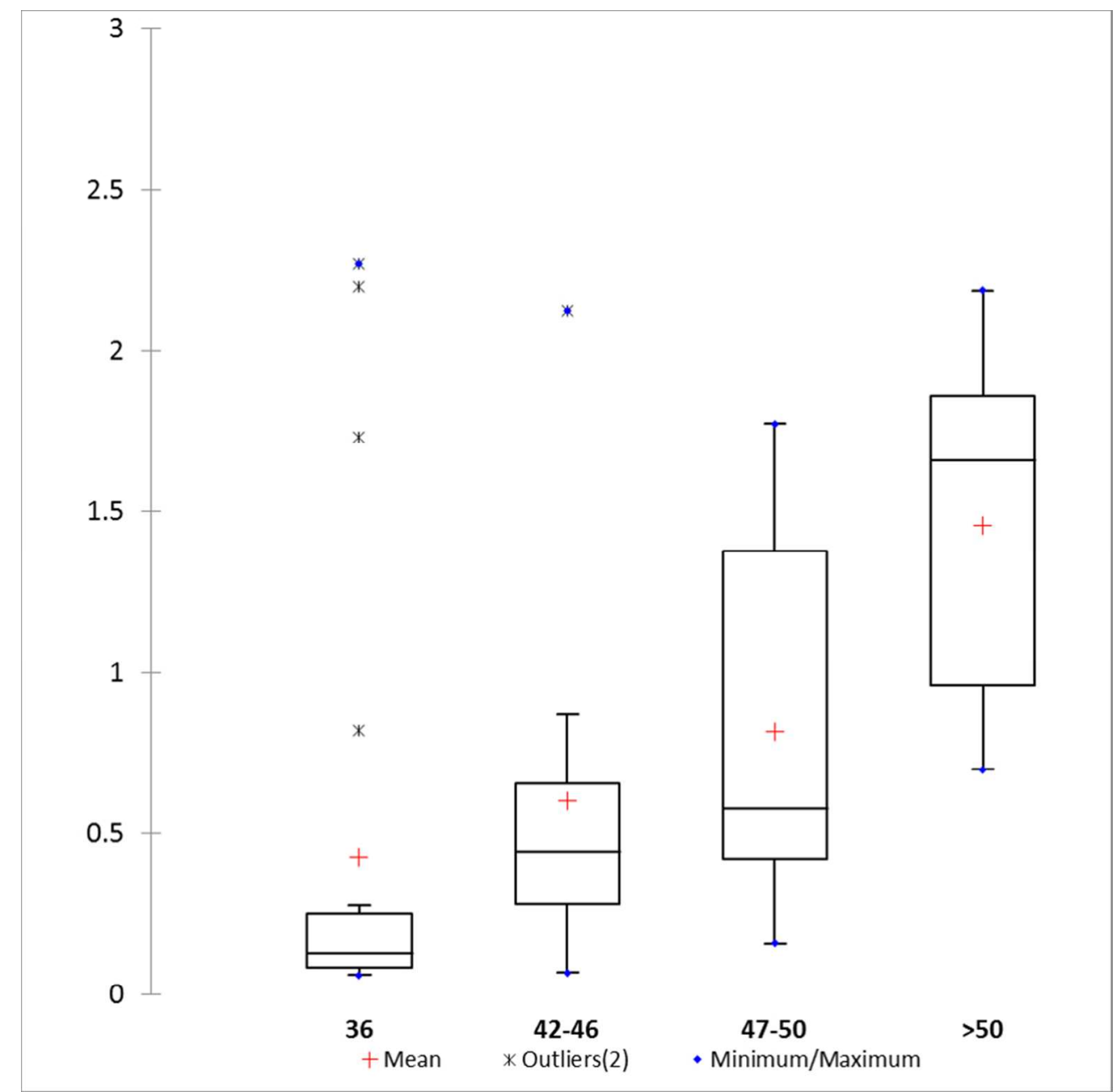

Figure 3: This box and whisker chart demonstrates the significant relationship between the bearing diameter and the rate of volumetric material loss from the taper junction. The size groups were selected to represent an equal spread of data.

$242 \times 239 \mathrm{~mm}(96 \times 96 \mathrm{DPI})$ 
Figure 4: This scatter chart shows the results of all the profilometry results obtained from measurement of explanted male tapers. Position 1 is the base (distal aspect) of the male taper and position 11 the very tip of the Ti tapers. Position 12 is not included on the chart as this position was only applicable to the CoCr stems. For all the values on each surface and on each group the data were pooled and a mean value calculated and plotted. In both groups, in the superior and inferior positions there was significant trend towards an increasing Ra value the closer to the tip the measurement was taken. A reduction in Ra indicated material loss, therefore wear was maximal at the base of the male tapers for both mixed and similar metal systems.

$157 \times 143 \mathrm{~mm}(96 \times 96 \mathrm{DPI})$ 
Figure 5: CMM generated wear maps from the two groups. Distribution of material loss was similar between the two groups and followed patterns we have previously described. 
Figure 6: SEM images recorded from typical female $\mathrm{Ti}$ (left) and $\mathrm{CoCr}$ (right) tapers. The heads have been upturned and the images focus on the transition between the unworn female surface and the area of maximum material loss (where the base of the male taper has worn into the surface). In both images, the visible regular machining marks of the original surface have been polished away deep to the engagement level. 
Figure 7: SEM images of the examined male Ti and CoCr tapers. In both cases the corresponding female tapers had lost approximately $1 \mathrm{~mm} 3$ of material. The images suggest greater wear of the $\mathrm{CoCr}$ taper compared to the $\mathrm{Ti}$, as the original machining marks of the Ti surfaces have been retained. This was confirmed with CMM and profilometry. 


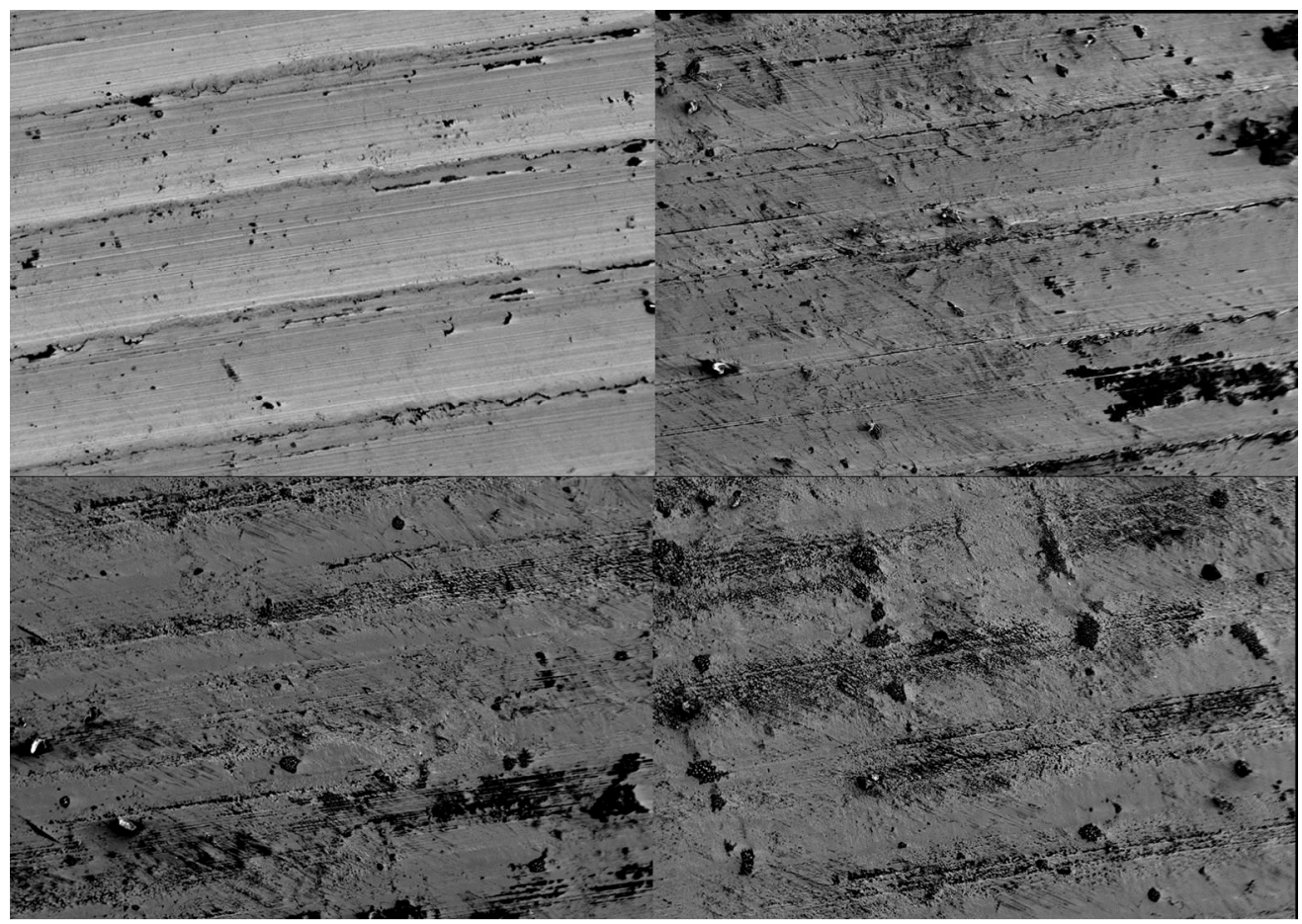

Figure 8: SEM of the CoCr male taper. The images have been taken at the same level of magnification. The images top left and top right were taken at the proximal end of the taper (inferior surface right, superior surface left). The bottom left and bottom right were taken at the distal end of the taper (inferior surface right, superior surface left). 


\section{Appendix: Measurement of material loss at taper surfaces}

Customised programmes were written using Mitutoyo 'MCOSMOS' software to measure the taper surfaces. As with analysis of bearing surfaces, identification of the original surface is vital in order to accurately determine the volumetric wear.

The bespoke CMM programme requires the user to enter three values in order to measure the taper. The first two values correspond to the lower and upper heights of the section of unworn surface. These values are determined from the analysis of the taper from base to rim using a Mitutoyo Surftest SJ400 profilometer. The profilometer provides a visual and quantitative assessment of the surface under examination. In the vast majority of female tapers a section remains unchanged as male tapers do not routinely engage with the full length of the female surface. It is relatively straightforward to determine the original unworn surface due to the ability of the profilometer to identify the regular machining pattern of the original surface. The final variable is the 'length', representing the total height of the taper over which measurements are to be taken.

The CMM programme works in three stages. The first stage identifies the initial coordinate system. The second stage generates a perfect theoretical cone representing the original perfect unworn surface. The third stage measures the entire surface and compares the data points with the perfect cone to determine any deviations, which represent wear depths, which are summed to calculate volumetric wear.

\section{Stage 1: Establishment of initial taper coordinate system.}

To perform the analysis, the femoral heads were overturned and held in position so the taper rims pointed to the ceiling. A $0.5 \mathrm{~mm}$ probe was used to perform the scans. Five equispaced circumferential traces were taken by the $\mathrm{CMM}$ around the taper at regular $\mathrm{Z}$ heights. Four linear traces were then taken over the full length of the taper at 90 degree intervals around the circumference. The initial $Z$ axis was based on the cone calculated by these traces, with the origin placed at the taper rim and the $X$ and $Y$ coordinates based on a plane perpendicular to the axis of the cone.

\section{Stage 2: Theoretical cone generation and definitive coordinate system.}

A series of 20 equispaced linear traces in the $Z X$ plane (with rotation about the $Z$ axis every 18 degrees) were then taken over the area identified as "unworn" by the operator. The straightness of each one of the 20 traces was calculated by the CMM. Those which were found to have deviations 
from straightness of less than 4.5 microns were used to calculate the angle of the original cone and also the $Z$ axis of the coordinate system, with the $Z$ axis being parallel to the axis of the perfect cone. 4.5 microns was chosen as the limit of straightness following analysis of several samples and consideration of variation in manufacturing processes. A minimum of five traces were required to continue the scans. If this was not achieved, the generated cone was not of sufficient precision to continue. In this case, the operator would have to reassess the area to scan in order to determine the original geometry of the cone. The definitive $Z$ axis, used in the final calculations, was based on the cone calculated by these traces, with the origin again placed at the taper rim and the $X$ and $Y$ coordinates based on a plane perpendicular to the axis of the cone.

\section{Stage 3: Data collection for calculation of wear.}

Once the critical " $Z$ axis" was established, 30 definitive linear scans were carried out in the ZX plane, with the coordinate system rotating through 12 degrees each time. A point pitch of 25 microns was used, meaning that over 10,000 data points were collected for the commonly used head offsets.

Once the co-ordinate data was collected from the $\mathrm{CMM}$, the individual data points were read into a bespoke Matlab program (The Mathworks, Inc.). First, the relevant data was extracted and split into matrices representing the Cartesian co-ordinates. These three matrices were used to create a three dimensional representation of the sample. In order to calculate linear wear depths, the distance from each measured point to the centreline of an ideal cone was calculated using the formula $\sqrt{X^{2}+Y^{2}}$ where $X$ and $Y$ were the Cartesian co-ordinates perpendicular to the cone's centreline (the $Z$ axis). This 'original' cone was positioned at the time of scanning (as described above), and all measurements were taken relative to it. The expected distance from the centreline of the cone to each point if the cone were unworn was also calculated (the "perfect" cone angle generated by the CMM was required for these calculations, as was the identification of an unworn $Z$ level from which to project). This distance varied depending on the height at which the point was measured. This was accounted for simply by factoring in the ' $\mathrm{Z}$ ' co-ordinate measured by the CMM. The difference between expected distance and measured distance gave linear wear depths. Once linear wear depths were known, the volumetric wear loss was calculated by multiplying the area of each gridsquare by the mean depths of the four measured points at its corners, as per the method described previously.(1)

This method was validated using gravimetric testing. Gravimetric measurements were performed using a Kern ACJ320-4M (Kern and Sohn GmbH, Ziegelei, Balingen, Germany) balance with a sensitivity of $0.1 \mathrm{mg}$. For the volumetric measurements, a Mitutoyo Legex $322 \mathrm{CMM}$ was used with a $0.5 \mathrm{~mm}$ diameter ruby stylus. Coordinate measurement machine and gravimetric measurements 
were performed by different authors as to blind the results. Gravimetric testing was always performed first with CMM measurements performed subsequently.

For each stage of wear, six gravimetric and a minimum of three separate CMM measurements were taken. Taper wear was simulated by removing increasing amounts of material using P240 grade sandpaper attached to a rotating tool. Care was taken to remove material of an amount and distribution to best represent explanted samples. For this reason, only $2.5 \mathrm{~mm}$ of unworn surface was left adjacent to the rim for the female taper samples. The heads were then cleaned using compressed air to ensure all wear particles had been removed. Gravimetric and volumetric measurements were then performed. More material was then removed in stages to simulate increasing amounts of wear and the measurements were repeated for the different stages of material loss. A total of three 'wear' stages were tested, including the unworn stage.

Once all measurements were completed, the volume loss determined gravimetrically was calculated by subtracting the mean of the six gravimetric measurements at each stage of material removal from the mean of the six values obtained prior to material removal. These values were then converted to volumes using the density values as previously reported.(2)

At the outset of our research in this area, the method of calculation of volumetric material loss from the female taper was examined using an unused Articuleze female taper. Subsequent to this initial validation, we examined the accuracy of the technique for volumetric loss of the male taper using three different stem designs.(2) The method of assessment of wear of male tapers uses essentially the same approach, the only difference being that the wear depth calculations are performed, in a sense, symmetrically: material loss of female tapers occurs from the inside out, leaving material further from the original cone axis; material loss of male tapers occurs from the outside in, leaving the remaining surface closer to the original cone axis). The technique and validation process was published in the Proceedings of the Institute of Mechanical Engineers: Journal of Engineering in Medicine(2). The results were similar to the previous tests on the female tapers. Analysis of the Corail, Exeter and Accolade stems allowed us to test that the methods remained sufficiently accurate even when smaller volumes were expected, when there was wide variation in the surface under examination (Ra value of approximately 0.3 microns for the Exeter stem taper versus 3.5 microns for the rough finish of the Corail stem taper) and using materials of different densities.

Most recently, we obtained one SROM and two Articuleze femoral heads of varying offsets $(+6,+8$ and +12 respectively $)$ and surface finishes $(\mathrm{Ra}=0.262, \mathrm{Rpk}=0.336 ; \mathrm{Ra}=0.966, \mathrm{Rpk}=0.436 ; \mathrm{Ra}=$ $0.470, \mathrm{Rpk}=0.385$ respectively) in order to conduct further gravimetric tests. This time only one $\mathrm{CMM}$ scan per sample was conducted, in order to best represent the methodology used in this 
paper. We routinely conduct only one CMM analysis per sample if the data is assessed using cross sectional and three dimensional wear mapping as well as presentation of the outputted coordinates in the form of a histogram and deemed satisfactory. This technique allows errors in volumetric calculations brought about by the alignment of the original geometry of the cone with respect to the longitudinal axis and cone angle. For these tests, only limited continuous areas of surface were left untouched so that the inputted upper and lower $Z$ values for the perfect cone assessment were restricted to 0 to $2.5 \mathrm{~mm}$.

The median (range) error in a total of 54 comparison tests was $0.05 \mathrm{~mm}^{3}\left(-0.32-0.24 \mathrm{~mm}^{3}\right.$ ) (negative values indicate under measurement of material loss using the CMM technique). The raw data from the validation studies is provided below. Three CMM tests were performed on unworn samples for all tests. In the original female taper validation study five CMM runs were performed for each wear stage. For the male taper study four CMM runs were performed, with scan results excluded if satisfactory data alignment was not achieved. This was determined as described above and in greater detail in relation to data fitting of bearing surfaces in a previous publication.(3)

\begin{tabular}{|c|c|c|}
\hline $\begin{array}{l}\text { Volume loss measured } \\
\text { gravimetrically }\left(\mathrm{mm}^{3}\right)\end{array}$ & $\begin{array}{c}\text { Volume loss as determined by } \\
\text { Matlab }\left(\mathrm{mm}^{3}\right)\end{array}$ & Sample \\
\hline 0.00 & 0.10 & Articuleze Head +1.5 \\
\hline 0.00 & 0.00 & Articuleze Head +1.5 \\
\hline 0.00 & 0.09 & Articuleze Head +1.5 \\
\hline 3.55 & 3.30 & Articuleze Head +1.5 \\
\hline 3.55 & 3.75 & Articuleze Head +1.5 \\
\hline 3.55 & 3.24 & Articuleze Head +1.5 \\
\hline 3.55 & 3.25 & Articuleze Head +1.5 \\
\hline 3.55 & 3.76 & Articuleze Head +1.5 \\
\hline 5.48 & 5.39 & Articuleze Head +1.5 \\
\hline 5.48 & 5.16 & Articuleze Head +1.5 \\
\hline 5.48 & 5.61 & Articuleze Head +1.5 \\
\hline 5.48 & 5.50 & Articuleze Head +1.5 \\
\hline 5.48 & 5.72 & Articuleze Head +1.5 \\
\hline 0.00 & 0.13 & Corail trunnion \\
\hline 0.00 & 0.13 & Corail trunnion \\
\hline 0.00 & 0.14 & Corail trunnion \\
\hline 0.16 & 0.34 & Corail trunnion \\
\hline 0.16 & 0.30 & Corail trunnion \\
\hline 0.16 & 0.28 & Corail trunnion \\
\hline 0.25 & 0.43 & Corail trunnion \\
\hline 0.25 & 0.42 & Corail trunnion \\
\hline 0.25 & 0.43 & Corail trunnion \\
\hline
\end{tabular}




\begin{tabular}{|c|c|c|}
\hline 0.25 & 0.37 & Corail trunnion \\
\hline 0.44 & 0.57 & Corail trunnion \\
\hline 0.44 & 0.56 & Corail trunnion \\
\hline 0.44 & 0.59 & Corail trunnion \\
\hline 0.44 & 0.50 & Corail trunnion \\
\hline 0.00 & 0.06 & Exeter V40 trunnion \\
\hline 0.00 & 0.04 & Exeter V40 trunnion \\
\hline 0.00 & 0.05 & Exeter V40 trunnion \\
\hline 0.21 & 0.25 & Exeter V40 trunnion \\
\hline 0.21 & 0.26 & Exeter V40 trunnion \\
\hline 0.21 & 0.27 & Exeter V40 trunnion \\
\hline 0.34 & 0.20 & Exeter V40 trunnion \\
\hline 0.34 & 0.32 & Exeter V40 trunnion \\
\hline 0.34 & 0.34 & Exeter V40 trunnion \\
\hline 0.34 & 0.37 & Exeter V40 trunnion \\
\hline 0.49 & 0.50 & Exeter V40 trunnion \\
\hline 0.49 & 0.52 & Exeter V40 trunnion \\
\hline 0.49 & 0.54 & Exeter V40 trunnion \\
\hline 0.49 & 0.52 & Exeter V40 trunnion \\
\hline 0.00 & 0.05 & Accolade trunnion \\
\hline 0.00 & 0.05 & Accolade trunnion \\
\hline 0.00 & 0.05 & Accolade trunnion \\
\hline 0.18 & 0.16 & Accolade trunnion \\
\hline 0.18 & 0.18 & Accolade trunnion \\
\hline 0.18 & 0.20 & Accolade trunnion \\
\hline 0.18 & 0.17 & Accolade trunnion \\
\hline 0.47 & 0.45 & Accolade trunnion \\
\hline 0.47 & 0.47 & Accolade trunnion \\
\hline 0.47 & 0.48 & Accolade trunnion \\
\hline 2.22 & 2.23 & Articuleze Head +8.5 \\
\hline 0.29 & 0.24 & SROM head +6 \\
\hline 9.48 & 9.59 & Articuleze Head + 12 \\
\hline
\end{tabular}

\section{Accuracy of gravimetric testing.}

The official figures given by the manufacturer of the balance used in this study quote a readability of $0.1 \mathrm{mg}$. How this relates to the practical experiments involved in the validation study is shown in the table below. Samples were weighed six times and a mean value calculated. As can be seen in the example below - the tests conducted on the stainless steel Exeter trunnion - measurements varied only small amounts. These variations equated to changes in volume of approximately $0.015 \mathrm{~mm}^{3}$. 


\begin{tabular}{|c|c|c|c|c|c|c|}
\hline Stage & & $\mathbf{g}$ & kg & $\begin{array}{l}\text { Density } \\
\mathrm{kg} / \mathrm{m}^{\wedge} 3\end{array}$ & $m^{\wedge} 3$ & $\mathrm{~mm}^{\wedge} 3$ \\
\hline \multirow[t]{7}{*}{ Unworn } & 1 & 29.0947 & 0.029094700 & 8000 & $3.6368 \mathrm{E}-06$ & 3636.837500 \\
\hline & 2 & 29.0948 & 0.029094800 & 8000 & 3.6369E-06 & 3636.850000 \\
\hline & 3 & 29.0948 & 0.029094800 & 8000 & $3.6369 \mathrm{E}-06$ & 3636.850000 \\
\hline & 4 & 29.0949 & 0.029094900 & 8000 & $3.6369 \mathrm{E}-06$ & 3636.862500 \\
\hline & 5 & 29.0949 & 0.029094900 & 8000 & 3.6369E-06 & 3636.862500 \\
\hline & 6 & 29.0948 & 0.029094800 & 8000 & 3.6369E-06 & 3636.850000 \\
\hline & Mean & 29.09482 & 0.029094817 & 8000 & $3.6369 \mathrm{E}-06$ & 3636.85208333 \\
\hline \multirow[t]{9}{*}{ Light wear } & 1 & 29.0941 & 0.029094100 & 8000 & $3.6368 \mathrm{E}-06$ & 3636.76250000 \\
\hline & 2 & 29.094 & 0.029094000 & 8000 & $3.6368 \mathrm{E}-06$ & 3636.75000000 \\
\hline & 3 & 29.0941 & 0.029094100 & 8000 & $3.6368 \mathrm{E}-06$ & 3636.76250000 \\
\hline & 4 & 29.094 & 0.029094000 & 8000 & $3.6368 \mathrm{E}-06$ & 3636.75000000 \\
\hline & 5 & 29.0941 & 0.029094100 & 8000 & $3.6368 \mathrm{E}-06$ & 3636.76250000 \\
\hline & 6 & 29.0942 & 0.029094200 & 8000 & $3.6368 \mathrm{E}-06$ & 3636.77500000 \\
\hline & & & & & & \\
\hline & Mean & 29.09408 & 0.029094083 & 8000 & $3.6368 \mathrm{E}-06$ & 3636.76041667 \\
\hline & & & 0 & & & \\
\hline \multirow{8}{*}{$\begin{array}{l}\text { Medium } \\
\text { wear }\end{array}$} & 1 & 29.0931 & 0.029093100 & 8000 & $3.6366 \mathrm{E}-06$ & 3636.63750000 \\
\hline & 2 & 29.0933 & 0.029093300 & 8000 & 3.6367E-06 & 3636.66250000 \\
\hline & 3 & 29.0932 & 0.029093200 & 8000 & 3.6367E-06 & 3636.65000000 \\
\hline & 4 & 29.0932 & 0.029093200 & 8000 & 3.6367E-06 & 3636.65000000 \\
\hline & 5 & 29.0933 & 0.029093300 & 8000 & $3.6367 E-06$ & 3636.66250000 \\
\hline & 6 & 29.0932 & 0.029093200 & 8000 & 3.6367E-06 & 3636.65000000 \\
\hline & Mean & 29.09322 & 0.029093217 & 8000 & 3.6367E-06 & 3636.65208333 \\
\hline & & & & & 2 & \\
\hline \multirow{7}{*}{$\begin{array}{l}\text { Heavy } \\
\text { wear }\end{array}$} & 1 & 29.0917 & 0.029091700 & 8000 & $3.6365 \mathrm{E}-06$ & 3636.46250000 \\
\hline & 2 & 29.0919 & 0.029091900 & 8000 & $3.6365 \mathrm{E}-06$ & 3636.48750000 \\
\hline & 3 & 29.0918 & 0.029091800 & 8000 & 3.6365E-06 & 3636.47500000 \\
\hline & 4 & 29.0918 & 0.029091800 & 8000 & 3.6365E-06 & 3636.47500000 \\
\hline & 5 & 29.0918 & 0.029091800 & 8000 & $3.6365 \mathrm{E}-06$ & 3636.47500000 \\
\hline & 6 & 29.0919 & 0.029091900 & 8000 & $3.6365 \mathrm{E}-06$ & 3636.48750000 \\
\hline & Mean & 29.09182 & 0.029091817 & 8000 & $3.6365 \mathrm{E}-06$ & 3636.47708333 \\
\hline
\end{tabular}




\section{Assessment of the Surface Roughness of the As Manufactured Taper Surface.}

Surface roughness parameters depend on the periodicity of the measured surface, the sampling length and the evaluation length. We wanted to choose an appropriate measurement combination for the surfaces under investigation. Almost all (93 out of the 95) samples had preserved, unworn areas greater than $2 \mathrm{~mm}$ in length which were free of debris. The as manufactured Ra value of the Pinnacle head taper should, according to publicly available manufacturing records be $<0.6$ microns. It is unknown whether it should be periodic. However, during our measurements it became clear that a number of explants exhibited surfaces with much greater roughness values and with exaggerated periodic profiles. After consideration of ISO standard 4288 Geometric Product Specification (GPS) - Surface texture - Profile method: Rules and procedures for the assessment of surface texture it was felt most appropriate that ideally a $4 \mathrm{~mm}$ evaluation length with sampling length of $0.8 \mathrm{~mm}$ should be used. However, as noted above, a number of explants did not have a total $4 \mathrm{~mm}$ length free of wear. Bearing this in mind, (as well as the fact that some authors have noted the inherent complications with interpretation of Rsm- "The case of surface texture parameter RSm. P J Scott Meas. Sci. Technol. 17 (2006) 559-564")(see tables below extracted from ISO 4288) we conducted a comparison study of the difference between a reduced $1.6 \mathrm{~mm}$ evaluation length (composed of two sets of $0.8 \mathrm{~mm}$ sampling lengths) versus a $4 \mathrm{~mm}$ evaluation length with the same sampling lengths.

The comparison study included the first 35 Pinnacle heads of -2 and 1.5 head offset (in order to ensure $>4 \mathrm{~mm}$ of unworn surface to be measured). The results of this comparison study are shown for Rpk (the main parameter under investigation) in Appendix figure 1 and for Ra in Appendix figure 2.

We found extremely good agreement between the two techniques, with both Ra and Rpk measurement correlations above $0.90(p<0.001)$. Bland Altman plots were constructed and deemed satisfactory for the purposes of the investigation. 
1. Langton DJ, Joyce TJ, Mangat N, Lord J, Van Orsouw M, De Smet K, et al. Reducing metal ion release following hip resurfacing arthroplasty. Orthop Clin North Am. 2011;42(2):169-80, viii.

2. Bone MC, Sidaginamale RP, Lord JK, Scholes SC, Joyce TJ, Nargol AV, et al. Determining material loss from the femoral stem trunnion in hip arthroplasty using a coordinate measuring machine. Proc Inst Mech Eng H. 2015;229(1):69-76.

3. Langton DJ, Sidaginamale RP, Holland JP, Deehan D, Joyce TJ, Nargol AV, et al. Practical considerations for volumetric wear analysis of explanted hip arthroplasties. Bone Joint Res.

2014;3(3):60-8. 